\title{
PERAN KEPUASAN PELANGGAN DALAM MEMEDIASI PENGARUH PERCEIVED VALUE TERHADAP LOYALITAS PELANGGAN HOTSPOT WIFI.ID DI DENPASAR
}

\author{
Jeremy Roy Agustin Ndoen ${ }^{1}$ \\ Ni Made Wulandari Kusumadewi ${ }^{2}$ \\ ${ }^{1,2}$ Fakultas Ekonomi dan Bisnis Universitas Udayana (Unud), Bali, Indonesia \\ e-mail : jeremyndoen26@gmail.com
}

\begin{abstract}
ABSTRAK
Penelitian dilakukan di Denpasar dengan menggunakan ukuran sampel sejumlah 110 orang dengan metode non-probability berbentuk purposive sampling. Teknik analisis data yang digunakan dalam penelitian ini yaitu path analyis serta uji sobel. Hasil penelitian menunjukkan bahwa perceived value berpengaruh positif dan signifikan terhadap kepuasan pelanggan, begitupun terhadap loyalitas pelanggan. Selanjutnyakepuasan pelanggan berpengaruh positif dan signifikan terhadap loyalitas pelanggan. Selain itu kepuasan pelanggan secara simultanmemediasi pengaruh perceived value terhadap loyalitas pelanggan. Hasil ini menggambarkan bahwa lingkungan pemasaran yang bersifat dinamis, sehingga untuk menjaga loyalitas pelanggan perusahaan diharapkan mampu menciptakan value sesuai dengan apa yang diharapkan para pelanggan sehingga timbul kepuasan.
\end{abstract}

Kata kunci : perceived value, kepuasan pelanggan, loyalitas pelanggan

\begin{abstract}
This research was conducted in Denpasar using a sample size of 110 people with method non-probability in the form of purposive sampling. Data analysis techniques used in this research is the path analyis and Sobel test. The results showed that perceived value have significant and positive effect on customer satisfaction, as well as on customer loyalty. Furthermore, customer satisfaction have positive and significant effect on customer loyalty. Besides customer satisfaction simultaneouslymediates the effect of perceived value on customer loyalty. These results illustrate that the marketing environment is dynamic, so as to maintain customer loyalty company is expected to create value in accordance with what is expected of the customers so that the resulting satisfaction.
\end{abstract}

Keywords : perceived value, customer satisfaction, customer loyalty 


\section{PENDAHULUAN}

Era digitalisasi saat ini merambah ke setiap aspek kehidupan masyarakat Indonesia, baik itu di sektor pendidikan, perekonomian bahkan pemerintahan. Hal ini tidak lepas dari peran industri telekomunikasi yang sadar akan kebutuhan masyarakat saat ini. Melihat hasil surveyyang dilakukanoleh Asosiasi PenyelenggaraJaringan InternetIndonesia (APJII) padatahun 2017 menunjukkan bahwalebih dari 50 persen atau setengah dari jumlah penduduk Indonesia kini telahterhubung keinternet. Hasil itu meningkat dibandingkan dengan hasil survei di tahun sebelumnya, seperti yang terlihat pada Gambar 1.Hal inilah yang menuntut perusahaan telekomunikasi di Indonesia untuk terus berkembang dan selalu mencermati apa yang dibutuhkan dan diinginkan pasar sasarannya agar tetap mampu bersaing. Salah satunya dengan mengembangkan berbagai inovasi terkini pada produknya, serta meningkatkan kualitas pelayanan sehingga diharapkan timbulnya kepuasaan di benak pelanggan. Seperti yang kita tahu pula, dengan melihat peningkatan jumlah pemakai jasa layanan internet dari tahun ke tahun, maka hal ini pula yang mendorong berkembangnya layanan-layanan baru yang dikembangkan perusahaan telekomunikasi untuk mempermudah konsumen dalam mengakses layanan internet.

PT. Telekomunikasi Indonesia Tbk. sebagai salah satu BUMN yang bergerak di sektor informasi dan komunikasi digital mencermati hal tersebut. BUMN melalui PT. Telekomunikasi Indonesia Tbk. (Telkom) berupaya mendorong pembangunan jaringan tulang punggung serta jaringan akses infrastruktur digital Indonesia untuk dimanfaatkan membangun Ekonomi Digital 
Indonesia termasuk bagi UMKM dalam mengakses market place (Kementerian BUMN, 2017).

\section{Gambar 1.}

Persentase Penetrasi Pengguna Internet di Indonesia Tahun 2016 dan 2017

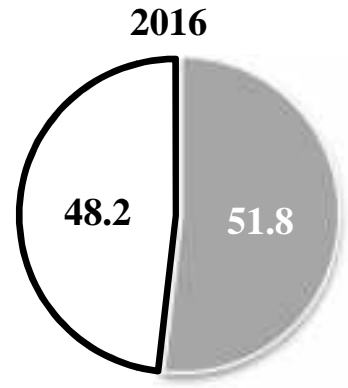

Total penduduk : 256,2 juta Penetrasi : $: 51,8 \%$

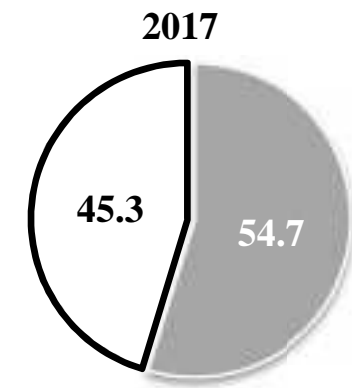

Total penduduk : 262 juta Penetrasi : $: 54,7 \%$

Sumber : APJII, 2017

Telkom meningkatkan pembangunan jaringan fiber optic, tower dan transmisi. Telkom berupaya mendorong adanya kesetaraan akses informasi melalui digitalisasi. Salah satunya dengan meluncurkan Indonesia Wifi atau yang dikenal dengan Wifi.Id yang menyediakan layanan internet publik berbasis teknologi Wifi Hotspot dalam rangka mendukung program pemerintah. Berdasarkan data dari Kementerian BUMN hingga 2017 Telkom telah membangun sekitar 362 ribu AP (Access Point) untuk layanan Hotspot Wifi.Id di seluruh Indonesia. Hotspot atau tempat akses internet dengan menggunakan wireless IEEE 802.11b sendiri memang sudah sangat banyak atau telah menjadi trend. Berbagai tempat umu seperti restoran, cafe bahkan hotel menyediakan layanan internet tanpa kabel ini. Hal ini disebabkan banyaknya perangkat yang 
telah dilengkapi dengan teknologi wireless, sehingga trend penggunaannya pun semakin tinggi.

Melihat peningkatan jumlah access point Wifi.Id dari tahun ketahun, maka dapat diasumsikan bahwa adanya reaksi positif dari pasar konsumen. Kebutuhan konsumen akan akses internet berkecepatan tinggi menjadi salah satu pertimbangan Wifi.Id untuk terus meningkatkan kualitas produknya. Pemilihan Wifi.Id sebagai objek dalam penelitian ini dikarenakan jumlah penggunanya yang sangat tinggi, sehingga tidak heran Wifi.Id saat ini menjadi market leader di segmennya. Selain itu, cakupan wilayah sebaran access point Wifi.Id yang sangat luas sehingga penting untuk mendalami aspek pemasarannya. Hasilnya cukup signifikan dengan indeks persentase kepuasan pelanggan Wifi.Id pada tahun 2016 seperti yang terlihat di Tabel 1, dimana tingkat kepuasan pelanggan Hotspot Wifi.Id pada setiap indikatornya memiliki indeks persentase di atas 80 persen.

Tabel 1.

Detail Persentase Customer Satisfaction Index (CSI) Wifi.Id tahun 2016

\begin{tabular}{ccc} 
& \multicolumn{2}{c}{ Persentase } \\
\cline { 2 - 3 } Indikator & Puas & Tidak Puas \\
\hline CSI & 87,57 & 1,47 \\
Product and Service & 86,20 & 1,80 \\
Delivery system & 87,80 & 2,10 \\
Service mindset & 85,10 & 2,00 \\
Relationship & 86,00 & 1,60 \\
Corporate images & 89,70 & 1,00 \\
\hline
\end{tabular}

Sumber : Laporan Keberlanjutan TELKOM, 2016

Indikator yang digunakan berkaitan dengan kualitas produk dan pelayanan yang diberikan perusahaan serta images perusahaan dibenak konsumen. Indeks tingkat kepuasan pelanggan Wifi.Id yang berada pada kisaran 80 persen keatas tentu menunjukkan adanya persepsi positif terhadap perusahaan di benak para 
pelanggannya. Tingginya indeks kepuasan tidak memaknai bahwa pelanggan juga loyal terhadap produk perusahaan. Hasil penelitian Putra (2016) pada layanan Hotspot Wifi.Id menunjukkan bahwa kualitas pelayanan berpengaruh signifikan terhadap kepuasan pelanggan namun tidak berpengaruh signifikan terhadap loyalitas pelanggan. Sehingga dapat disimpulkan bahwa tingginya indeks kepuasan tidak selalu memaknai bahwa pelanggan juga loyal terhadap produk perusahaan. Hal itu karena kepuasan dari pelanggan tidak selalu menimbulkan hubungan yang signifikan dengan loyalitas. Perusahaan harus beradaptasi dengan lingkungan pemasaran yang bersifat dinamis, termasuk dengan hadirnya pesaing. Seperti yang terlihat pada Tabel 2 bagaimana pola hubungan antara kepuasan pelanggan dan loyalitas pelanggan.

Tabel 2.

Keterkaitan Antara Kepuasan Pelanggan danLoyalitasPelanggan

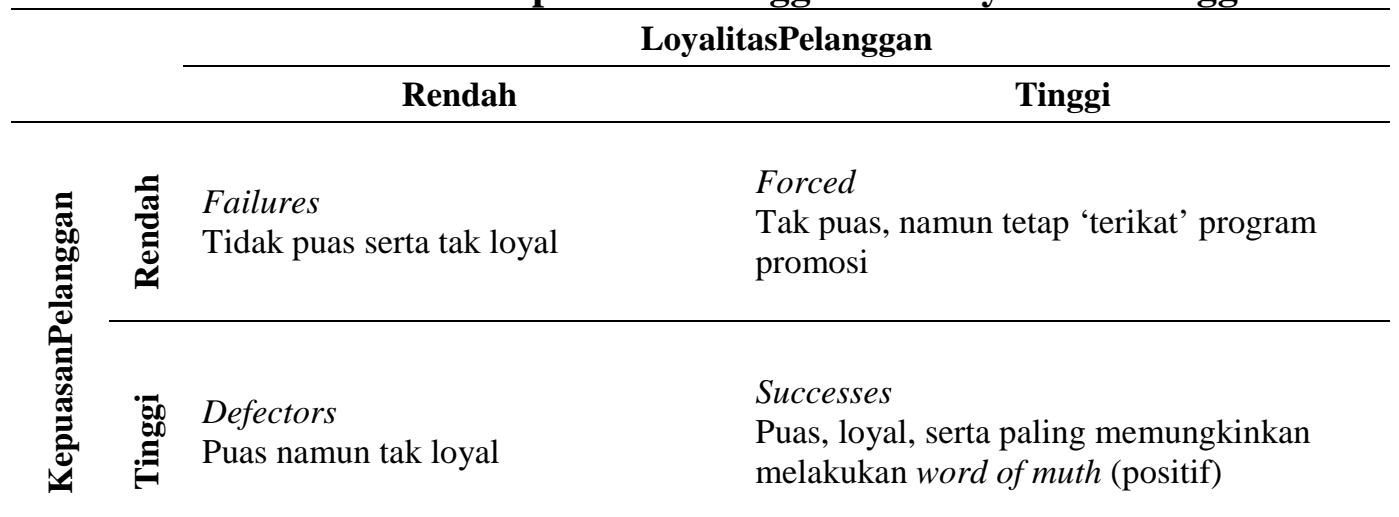

Sumber: Hasan Ali, 2013

Kepuasan yang dimiliki pelanggan juga perlu dipelihara dan ditingkatkan guna menciptakan dan mempertahankan kesetiaan konsumen terhadap merek tersebut (Wijaya dan Nurcaya, 2017). Faktor kepuasan saja tidak cukup untuk meneliti tentang aspek loyalitas pelanggan (Dabholkar dan Walls 1999), oleh 
karena itu penelitian-penelitian lain mencoba menyertakan variabel lain yang menjadi anteseden loyalitas pelanggan.

Membangun suatu loyalitas tidaklah mudah dan instant, dalam membangun suatu loyalitas dimulai dari menciptakan value, kepuasan serta loyalitas (Barnes, 2011:41). Artinya pemasar harus berhubungan dengan konsumen untuk berproses dalam menciptakan suatu nilai tambah, bahkan membuat mereka menikmati produk atau jasanya, serta menjadikan mereka konsumen yang loyal. Meningkatnya nilai bagi konsumen berpengaruh terhadap tingkat kepuasan. Tingkat kepuasan yang semakin meningkat tentunya akan membuat konsumen mengambil keputusan untuk tetap bertahan pada produk maupun jasa tersebut.

Banyak argumentasi yang muncul mengenai konsep perceived value dan kepuasan pelanggan. Woodruff dan Gardial (1996:98) menyatakan bahwa perceived value serta kepuasan pelanggan adalah dua point penting yang saling melengkapi satu sama lain, namun merupakan dua pokok yang berbeda. Berikut perbedaan konseptual antara kepuasan pelanggan serta perceived value.

Tabel 3.

Perbedaan Konseptual antara Kepuasan Pelanggandan Customer Perceived Value

\begin{tabular}{c|c}
\hline Customer Satisfaction & Customer Perceived Value \\
\hline Affective construct & Cognitive \& affective construct \\
Post-purchase perspective & Pre/post-purchase perspective \\
Tactical orientation & Strategic orientation \\
Present customer & Present \& potential customer \\
Supplier'saoffering & Supplieri\& competitorsioffering \\
\hline
\end{tabular}

Sumber: Woodruff dan Gardial, 1996 
Berdasarkan Tabel 3 dapat disimpulkan bahwadibutuhkanpemahaman yanglebih mendalam terhadap perceivedvalue tidakhanya dalam jangka waktu pendek, tapi juga memenuhi apa yang menjadi harapan pelanggan dalamhubungan jangka panjang (Ravald dan Gronroos, 1996). Perceived value konsumen akan berbeda saat didasarkan dalam sebuah episode spesifik apabila dibandingkan dengan hubungan jangka panjang. Kasus pertama, aspek-aspek yang paling berharga dari perceived value adalah komponen-komponen maupun manfaatmanfaat (kualitas produk superior, brand/image layanan pendukung, dsb); dalam long-term relationship, manfaat-manfaat akan menjadi semakin dalam (keselamatan, kredibilitas, keamanan, kontinuitas, dsb), lalu berevolusi melalui kepercayan terhadap para supplier yang mendorong loyalitas konsumen (Castro et al., 2004). Nilai inilah yang akan menjadi kunci dari loyalitas pelanggan, yang mempengaruhi keinginan pelanggan untuk melakukan pembelian (Moliner et al., 2007; Hasan et al., 2014). Didefinisikan secara luas, perceived value adalah benefit yang didapatkan customer berkaitan dengan total cost (termasukharga yangdibayar ditambah biaya lainterkait pembelian) (Woodruff, 1997). Menurut Wijaya et al. (2013) perceivedvalue adalah suatu usaha konsumen dalam membandingkan produk/jasa dari perusahaan tertentu dengan perusahaan pesaing ditinjau dari manfaat, kualitas dan harga. Perceived value adalah konsep yang sangat subjektif, namun merupakan nilai yang tampaknya sangat personal, istimewa, dan mungkin sangat bervariasi dari satu pelanggan ke pelanggan yang lain (Zeithaml, 1988). Dewasa ini perceived value telah mendapatkan perhatian sebagai suatu konstruksi yang stabil untuk dapat memprediksi perilaku pembelian 
konsumen (Parasuraman dan Grewal, (2000); Hellier et al. (2003); Mosavi dan Ghaedi, (2011); Lee dan Overby, (2004) dan Kanagal (2009) menyatakan bahwa menciptakan suatu nilai pelanggan adalah metode utama untuk membangun keunggulan kompetitif dalam suatu perusahaan.

Beberapa peneliti di bidang marketing yang sebelumnya pernah menguji pengaruh perceived value terhadap loyalitas pelanggan masih menemukan kesimpulan yang berbeda-beda. Chen dan Tsai (2008); Shoki et al. (2012) serta $\mathrm{Tu}$ et al. (2013) menghasilan temuan bahwa perceived value berpengaruh langsung dan signifikan terhadap loyalitas pelanggan. Hasil tersebut tidak konsisten dengan temuan dari Yeung dan Leung (2012); Candra dan Bernarto (2012); Sugiati et al. (2013); Kassim et al. (2014) dan Gultom dkk. (2016) yang menyatakan bahwa pengaruh langsung perceived value terhadap loyalitas pelanggan, dimana tidak memperoleh hasil yang signifikan. Berbeda halnya dengan penelitian yang dilakukan Boonlertvanich (2011) dan Chung dan Lee (2013) yang menemukan pengaruh langsung perceived value terhadap loyalitas pelanggan memberikan hasil yang signifikan, akan tetapi koefisien pengaruh langsung lebih rendah dibanding total pengaruh tidak langsung yang dimediasi kepuasan pelanggan. Hasil penelitian dibidang marketing seringkali hadir dalam bentuk pengaruh tidak langsung antar dua variabel atau lebih dimana dimediasi atau diperantarai oleh fenomena lainnya. Sebagai contoh penelitian yang dilakukan Tanujaya (2013) dan El-Adly dan Eid (2016), bahwa kepuasan pelanggan berperan sebagai variabel intervening dari pengaruh perceived value terhadap loyalitas pelanggan. 
Melihat research gap yang terjadi, menarik untuk meneliti lebih lanjut apakah hubungan antara perceived value dengan loyalitas pelanggan sebatas pengaruh langsung atau pengaruh tidak langsung yang dimediasi oleh kepuasan pelanggan itu sendiri.

Berdasarkan penelitian Chen dan Tsai (2008); Meng et al. (2011); Awwad (2012);Tu, Li dan Chih (2013) dan Rahab et al. (2015) menyimpulkan bahwa perceived value pelanggan memiliki pengaruh positif dan signifikan terhadap kepuasasn pelanggan. Sesuai dengan hasil penelitian empiris tersebut, maka dapat ditarik hipotesis sebagai berikut:

$\mathrm{H}_{1}$ : Perceived value berpengaruh positif signifikan terhadap kepuasan pelanggan.

Berdasarkan penelitian Luarn danLin (2003); Chen dan Tsai (2008); Shoki et al. (2012); Tu et al. (2013) serta Bernarto dan Patricia (2017) menunjukkan bahwa perceived value secara langsung berpengaruh positif dan signifikan terhadap loyalitas pelanggan. Sesuai dengan hasil penelitian empiris tersebut, maka dapat ditarik hipotesis sebagai berikut :

$\mathrm{H}_{2}$ : Perceived valueberpengaruh positif signifikan terhadap loyalitas pelanggan.

Penelitian Briliana (2013); Sawitri dkk. (2013); Rahab et al. (2015); Setiawan dkk. (2016); Palupi (2017) dan El-Adly (2018) menyimpulkan bahwa kepuasan pelanggan mempunyai pengaruh yang positif dan signifikan terhadap loyalitas pelanggan. Sesuai dengan hasil penelitian empiris tersebut, maka dapat ditarik hipotesis sebagai berikut :

$\mathrm{H}_{3}$ : Kepuasan pelanggan berpengaruh positif signifikan terhadap loyalitas pelanggan. 
Hasil penelitian Yang dan Peterson (2004); Shoki et al. (2012); Tanujaya (2013); Rahab et al. (2015); El-Adly dan Eid (2016); serta Tama dan Untoro (2016) menemukan bahwa kepuasan pelanggan berperan positif sebagai variabel mediasi pada pengaruh perceived value terhadap loyalitas pelanggan. Sesuai dengan hasil penelitian empiris tersebut, maka ditarik hipotesis sebagai berikut:

$\mathrm{H}_{4}$ : Kepuasan pelanggan secara simultan memediasi pengaruh perceivedvalue terhadap loyalitas pelanggan.

Berlandaskanpada kajian pustaka juga hasil studi empiris sebelumnya, sehingga dapat disusun kerangka konseptual seperti pada Gambar 2.

Gambar 2.

Kerangka Konseptual Peran Kepuasan Pelanggan dalam Memediasi Pengaruh Perceived Value Terhadap Loyalitas Pelanggan

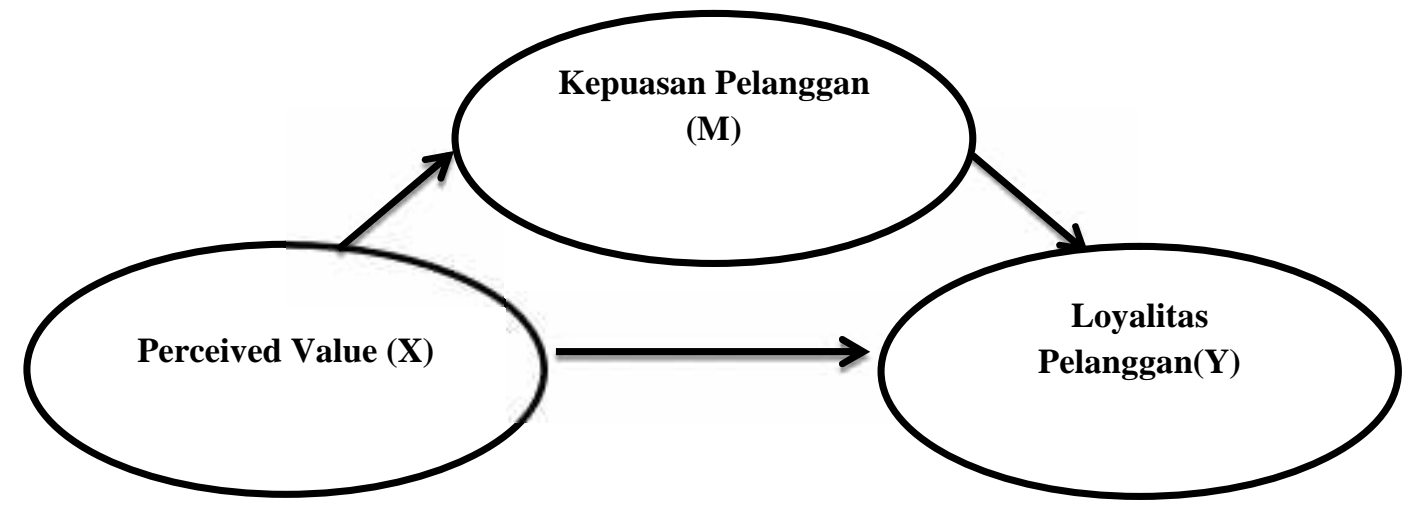

Sumber : Sugiati et al., 2013.

\section{METODEPENELITIAN}

Penelitianini menggunakan jenis pendekatankuantitatif dengan jenis penelitian yang bersifat asosiatif kausal. Penelitian kali ini bertujuan menguji hubungan sebab-akibat antara perceived value terhadap loyalitas pelanggan yang dimediasi oleh kepuasan daripada pelanggan Hotspot Wifi.Id di Denpasar dengan menggunakan metode survei melalui penyebaran kuesioner. Objek yang akan 
diteliti disini adalah loyalitas dari pelanggan yang dipengaruhi oleh persepsi nilaiserta kepuasan pelanggan itu sendiri. Variabel-variabel yang digunakan dalam penelitian ini adalah perceived value (X) sebagai variabel bebas (independen), loyalitas pelanggan (Y) sebagai variabel terikat (dependen) dan kepuasan pelanggan (M) sebagai variabel intervening. Terdapat 11 indikator yang digunakan untuk mengukur seluruhvariabel tersebut.

\section{Tabel 4.}

\section{IndikatorPenelitian}

\begin{tabular}{|c|c|c|c|}
\hline No & Variabel & Indikator & Sumber \\
\hline 1. & $\begin{array}{l}\text { Perceived } \\
\text { value } \\
\text { (X) }\end{array}$ & $\begin{array}{l}\text { 1) Produk memberi nilai tambah. } \\
\text { 2) Layak membayar lebih untuk mendapat produk. } \\
\text { 3) Produk dapat memenuhi kebutuhan. } \\
\text { 4) Produk memberikan manfaat lebih besar dibanding } \\
\text { biaya yang dikeluarkan. }\end{array}$ & $\begin{array}{c}\text { Wu dan } \\
\text { Chen (2014) }\end{array}$ \\
\hline 2. & $\begin{array}{c}\text { Kepuasan } \\
\text { Pelanggan } \\
\text { (M) }\end{array}$ & $\begin{array}{l}\text { 1) Pelanggan merasa senang setelah menggunakan } \\
\text { produk. } \\
\text { 2) Pelanggan merasa puas terhadap keseluruhan } \\
\text { pelayanan yang diberikan. } \\
\text { 3) Terpenuhinya harapan pelanggan setelah } \\
\text { menggunakan produk. }\end{array}$ & $\begin{array}{l}\text { Wulandari } \\
\text { dan } \\
\text { Rahyuda } \\
(2016)\end{array}$ \\
\hline 3. & $\begin{array}{c}\text { Loyalitas } \\
\text { Pelanggan } \\
\text { (Y) }\end{array}$ & $\begin{array}{l}\text { 1) Kesediaan berbelanja kembali. } \\
\text { 2) Kesediaan merekomendasikan kepada kerabat. } \\
\text { 3) Menjadikan perusahaan sebagai prioritas utama. } \\
\text { 4) Kesediaan membicarakan hal positif tentang } \\
\text { perusahaan. }\end{array}$ & $\begin{array}{c}\text { Orel dan } \\
\text { Kara (2014) }\end{array}$ \\
\hline
\end{tabular}

Populasi penelitian ini yaitu konsumen yang pernah menggunakan layanan Wifi.Id. di wilayah kota Denpasar. Jumlah indikator dalam penelitian ini adalah sebanyak 11 dengan pengukuran sampel yang representatif dikalikan 5 sampai dengan 10, maka ukuran sampelnya berada pada rentang 55-110. Berdasarkan pertimbangan maka jumlah sampel yang dibutuhkan dalam penelitian ini sebanyak 110 responden, menggunakan tekniknonprobabilitysampling dengan metode purposive sampling, yaitu proses penentuansampel dilakukan denganbeberapa pertimbangan. Pertimbangankriteria penentuan sampeldalam 
penelitianini diantaranya jenjang pendidikan minimal SMA/sederajat serta minimal pernah membeli atau menggunakan layanan Wifi.Id di wilayah kota Denpasar dalam rentang waktu satu bulan terakhir. Metode pengumpulan data dalam penelitian kali ini dilakukan dengan cara penyebaran instrumen penelitian berupa kuesioner atau angket dapat dilakukan baik secara langsung bertemu dengan pelanggan Wifi.Id.

Terdapat dua jenis data dalam penelitian ini yaitu data kualitatif yang berupa informasi dari responden mengenai pernyataan ataupun pertanyaan yang tertera di dalam kuesioner maupun informasi dari sumber sekunder, berikutnya data kuantitatif yang berupa laporan serta data statistik dari lembaga APJI serta PT. Telkom.

Sumber data yang digunakan terdiri dari sumber primer yaitu hasil jawaban responden atas pernyataan-pernyataan kuesioner terkait variabel-variabel yang dipergunakan dalam penelitian, serta sumber sekunder yang bersumber dari publikasikan data dari lembaga maupun institusi yang yang menjadi kutipan dalam latar belakang penelitian ini, seperti: Telkom.co.id, APJII.or.id dan media media lainnya. Data dikumpulkan menggunakan instrumen penelitian berupa kuesioner. Kuesioner terdiri dari pernyataan terbuka mengenai sejumlah pernyataan yang meminta pendapat responden tentang penilaian terhadap sejumlah indikator dari setiap variabel yang terdapat dalam kuesioner serta pernyataan tertutup mengenai identitas responden seperti nama, usia, jenis kelamin, dan pekerjaan responden. 
Pernyataan yang terdapat pada instrumen penelitian (kuesioner) nantinya diberikan pilihan dengan skala likert antara 1 sampai dengan 5. Sebelum digunakan, instrumen penelitian diuji validitas dan reliabilitasnya terlebih dahulu. Pernyataan-pernyataan dalam instrument penelitian dikatakan valid apabila koefisien korelasi $\geq 0,3$ (Sugiyono, 2016:142). Uji validitas instrumen bertujuan untuk memeriksa apakah instrumen penelitian (kuesioner) sudah tepat dalam mengukur indikator penelitian. Uji reliabilitasdilakukan untuk mengetahui konsistensi alat ukur yang dipergunakan, sehingga apabila dipergunakan kembali maka akan memperoleh hasil yang sama.Pernyataan-pernyataan dalam instrument penelitian dapat dinyatakanreliable jikakoefisien alphacronbach $\geq 0,6$ (Sugiyono, 2016:147).

Terdapat dua teknik analisis data dalam penelitian ini, yaitu statistik deskriptif serta inferensial. Statistika deskriptif digunakan untukmenyajikan deskripsi profil dari responden serta pendapat atau penilaian responden terhadap masing-masing pertanyaan ataupun pernyataan yang ada dalam kuisioner, dimana yang digunakan adalah distribusi frekuensi dan rata-rata nilai. Statistik inferensial digunakan untuk mengambil kesimpulan-kesimpulan berdasarkan data sampel yang lebih sedikit menjadi kesimpulan yang lebih umum dari populasi yang ada. Teknik analisis yang digunakan untuk statistik inferesial dalam penelitian ini adalah Path Analysis (Analisis jalur) dan Uji Sobel. 


\section{HASIL DAN PEMBAHASAN}

Jumlah sampel yang digunakan dalam penelitian ini yaitu sebanyak 110 orang yang diperoleh dari penyebaran kuisioner secara langsung. Karakteristik sampel ditinjau dari variabel demografi (jenis kelamin, umur, dan pekerjaan) yang ditunjukan pada Tabel 5 .

Tabel 5.

Karakteristik Demografi Sampel Penelitian

\begin{tabular}{lllll}
\hline No. & Kriteria & Klasifikasi & Jumlah (orang) & $\begin{array}{l}\text { Persentase } \\
(\boldsymbol{\%})\end{array}$ \\
\hline 1. & Jenis Kelamin & Laki-laki & 76 & 69 \\
& & Perempuan & 34 & 31 \\
& & Jumlah & $\mathbf{1 1 0}$ & $\mathbf{1 0 0}$ \\
\hline 2. & Umur & 17-21 tahun & 80 & 73 \\
& & $22-26$ tahun & 24 & 22 \\
& & 27 tahun keatas & 06 & 05 \\
\hline 3. & Pekerjaan & Jumlah & $\mathbf{1 1 0}$ & $\mathbf{1 0 0}$ \\
& & Pelajar/ Mahasiswa PNS & 88 & 80 \\
& & Swasta & 14 & 13 \\
& & Lainnya & 08 & 07 \\
& & Jumlah & $\mathbf{1 1 0}$ & $\mathbf{1 0 0}$ \\
\hline
\end{tabular}

Sumber : Data primer, 2018.

Berdasarkan hasil data pada Tabel 5 dapat digambarkan bahwa responden dalam penelitian ini didominasi oleh laki-laki yaitu sebanyak $69 \%$, sementara sisanya yaitu sebanyak $31 \%$ berjenis kelamin perempuan. Hasil sebaran ini dapat berarti bahwa lebih banyak konsumen laki-laki yang menggunakan Hotspot Wifi.Id dibanding dengan konsumen perempuan saat penyebaran kuesioner dilakukan.

Berdasarkan kriteria umur yang ditentukan, responden dengan rentang umur 17 sampai 21 tahun mendominasi sebaran kuesioner ini, yaitu sebesar 73\%. Hal tersebut menunjukan bahwa mayoritas responden berada pada rentang usiaremaja. Sisanya responden dengan rentang usia 22 sampai 26 tahun sebesar $22 \%$ serta responden dengan rentang usia 27 tahun keatas sebesar 5\%. 
Berdasarkan klasifikasi pekerjaannya, jumlah responden yang berstatus pelajar atau mahasiswa mendominasi sebaran kuesioner dengan persentase sebesar $80 \%$. Sisanya responden dengan klasifikasi pekerjaan swasta yaitu sebesar $13 \%$ serta lainnya sebesar $7 \%$. Hal ini menunjukan bahwa animo masyarakat di kalangan pelajar ataupun mahasiswa untuk menggunakan Hotspot Wifi.Id sangatlah tinggi.

Tabel 6.

Hasil Uji Validitas

\begin{tabular}{cccc}
\hline Variabel & Instrumen & Pearson Correlation & Keterangan \\
\hline \multirow{3}{*}{ Perceived Value } & X.1 & 0,749 & Valid \\
(X1) & X.2 & 0,813 & Valid \\
& X.3 & 0,591 & Valid \\
& X.4 & 0,747 & Valid \\
\hline \multirow{2}{*}{ Kepuasan Pelanggan } & M.1 & 0,727 & Valid \\
(M) & M.2 & 0,858 & Valid \\
& M.3 & 0,849 & Valid \\
\hline \multirow{2}{*}{ Loyalitas Pelanggan } & Y.1 & 0,843 & Valid \\
(Y) & Y.2 & 0,771 & Valid \\
& Y.3 & 0,815 & Valid \\
& Y.4 & 0,708 & Valid
\end{tabular}

Sumber : Data Primer, 2018.

Hasil perolehanuji validitas instrument penelitian padaTabel 6 memperlihatkan bahwaseluruh indikator pernyataan yang terdapat dalam variabel perceived value, kepuasanpelanggan sertaloyalitas pelanggan memilikinilai Pearson Correlationyang lebihbesar dari angka0,30 maka dari itusyarat validitasdata seluruh indikator tersebut terpenuhi.

Tabel 7.

HasilUji Reliabilitas

\begin{tabular}{ccc}
\hline Variabel & Cronbach'sAlpha & Keterangan \\
\hline Perceived Value & 0,707 & Reliabel \\
Kepuasan Pelanggan & 0,744 & Reliabel \\
Loyalitas Pelanggan & 0,790 & Reliabel \\
\hline
\end{tabular}

Sumber: Data primer, 2018. 
Hasil perolehan uji reliabilitasinstrumen penelitian pada Tabel7 memperlihatkan bahwaketiga instrumentpenelitian yaitu perceived value, kepuasanpelanggan, serta loyalitaspelanggan memilikijumlah koefisienalphacronbach'syang lebihbesar dari angka 0,60 maka dari itusyarat realibilitas seluruh instrument pada penelitianterpenuhi.

Deskripsi data variabel menggambarkan penilaian dari pernyataan yang terdapat dalam kuesioner penelitian. Rata-rata skor dari jawaban responden akan dinilai berdasarkan kriteria yang telah disajikan pada Tabel 8 sebagai berikut :

Tabel 8.

Tabel Statistik Deskriptif

\begin{tabular}{|c|c|c|c|c|c|c|c|}
\hline \multirow{2}{*}{ Indikator } & \multicolumn{5}{|c|}{ Skor Jawaban } & \multirow{2}{*}{ Jumlah Skor } & \multirow{2}{*}{ Rata-rata } \\
\hline & 1 & 2 & 3 & 4 & 5 & & \\
\hline $\mathrm{X1}$ & 0 & 0 & 16 & 56 & 38 & 462 & 4,20 \\
\hline $\mathbf{X} 2$ & 0 & 0 & 38 & 46 & 26 & 428 & 3,89 \\
\hline $\mathbf{X 3}$ & 0 & 0 & 2 & 66 & 42 & 480 & 4,36 \\
\hline \multirow[t]{2}{*}{$\mathrm{X4}$} & 0 & 0 & 12 & 54 & 44 & 472 & 4,29 \\
\hline & \multicolumn{5}{|c|}{$\mathbf{X}$} & & 4,19 \\
\hline M1 & 0 & 0 & 6 & 68 & 36 & 470 & 4,27 \\
\hline M2 & 0 & 0 & 18 & 68 & 24 & 446 & 4,05 \\
\hline \multirow[t]{2}{*}{ M3 } & 0 & 0 & 22 & 64 & 24 & 442 & 4,02 \\
\hline & \multicolumn{5}{|c|}{$\mathbf{M}$} & & 4,12 \\
\hline Y1 & 0 & 0 & 20 & 48 & 42 & 462 & 4,20 \\
\hline Y2 & 0 & 0 & 24 & 56 & 30 & 446 & 4,05 \\
\hline $\mathbf{Y 3}$ & 0 & 0 & 50 & 38 & 22 & 412 & 3,75 \\
\hline \multirow[t]{3}{*}{ Y4 } & 0 & 0 & 30 & 50 & 30 & 440 & 4,00 \\
\hline & \multicolumn{5}{|c|}{$\mathbf{Y}$} & & 4,00 \\
\hline & \multicolumn{5}{|c|}{ Total } & & 4,10 \\
\hline
\end{tabular}

Sumber: Data primer, 2018.

Hasil perhitungan Tabel 8 menunjukan bahwa rata-rata persepsi responden mengenai variabel perceived value secara keseluruhan adalah sebesar 4,19 sehingga masuk dalam kriteria cukup tinggi. Artinya responden mempunyai persepsi bahwa layanan Wifi.Id mampu memberikan value bagi para penggunanya. 
Hasil perhitungan Tabel 8menunjukan bahwa rata-rata persepsi responden mengenai variabel kepuasan pelanggan secara keseluruhan adalah sebesar 4,12 sehingga masuk dalam kriteria cukup tinggi. Artinya responden mempunyai persepsi bahwa layanan Wifi.Id mampu memberikan kepuasan bagi para penggunanya.Hasil perhitungan Tabel 8 menunjukan bahwa rata-rata persepsi responden mengenai variabel loyalitas pelanggan secara keseluruhan adalah sebesar 4,00 sehingga masuk dalam kriteria cukup tinggi. Artinya responden mempunyai persepsi bahwa layanan Wifi.Id mampu membuat para penggunanya untuk tetap loyal.

Perhitungan koefisien path pada analisis jalur dilakukan dengan analisis regresi melalui software IBM SPSS Statistic 24.0. Hasil perolehan dirangkum pada Tabel 9 dan Tabel 10.

Tabel 9.

Hasil Path Analysis Persamaan Regresi I

\begin{tabular}{cccc}
\hline \multirow{2}{*}{ Model } & \multirow{2}{*}{ R Square } & Standardized Coefficients & \multirow{2}{*}{ Sig. } \\
\cline { 3 - 3 } & & Beta & \\
\hline Perceived Value & 0,380 & 0,617 & 0,000 \\
\hline
\end{tabular}

Sumber : Data Primer, 2018.

Sesuai dengan hasil Path Analysis substruktural 1 pada Tabel 9, maka persamaan strukturalnya adalah:

$$
\begin{aligned}
& M=\beta_{1} X+e_{1} \ldots \\
& M=0,617 X+e_{1}
\end{aligned}
$$

Nilai $\beta_{1}$ yaitu sebesar 0,617 mempunyai arti perceived value berpengaruh positif terhadap kepuasan pelanggan, dengan kata lain apabila faktor perceived value meningkat maka kepuasan pelanggan meningkat sebesar 0,687. 
Tabel 10.

Hasil Path Analysis Persamaan Regresi II

\begin{tabular}{|c|c|c|c|}
\hline \multirow[b]{2}{*}{ Model } & \multirow{2}{*}{ R Square } & Standardized Coefficients & \multirow[b]{2}{*}{ Sig. } \\
\hline & & Beta & \\
\hline Perceived Value & \multirow{2}{*}{0,607} & 0,446 & 0,000 \\
\hline Kepuasan Pelanggan & & 0,421 & 0,000 \\
\hline
\end{tabular}

Sumber : Data Primer, 2018.

Sesuai dengan hasil Path Analysis substruktural 2, maka persamaan strukturalnya adalah:

$$
\begin{aligned}
& Y=\beta_{2} M+\beta_{3} X+e_{2} \ldots \ldots \ldots \\
& Y=0,446 M+0,421 X+e_{2}
\end{aligned}
$$

Keterangan :

$$
\begin{array}{ll}
\mathrm{X} & =\text { Perceived value } \\
\mathrm{M} & =\text { Kepuasan pelanggan } \\
\mathrm{Y} & =\text { Loyalitas pelanggan } \\
\beta & =\text { Koefisien garis regresi } \\
\mathrm{e}_{1} & =\text { error } 1 \\
\mathrm{e}_{2} & =\text { error } 2
\end{array}
$$

Nilai $\beta_{2}$ yaitu sebesar 0,446 mempunyai arti perceived value berpengaruh positif terhadap loyalitas pelanggan, dengan kata lain apabila faktor perceived value meningkat maka loyalitas pelanggan meningkat sebesar 0,446 . Nilai $\beta_{3}$ yaitu sebesar 0,421 mempunyai arti kepuasan pelanggan berpengaruh positif terhadap loyalitas pelanggan, dengan kata lain apabila faktor kepuasan pelanggan meningkat maka loyalitas pelanggan meningkat sebesar 0,421.

Berdasarkan model substruktural 1 dan substruktural 2, maka dapat disusun model diagram jalur akhir. Sebelum itu, terlebih dahulu dilakukan perhitungan nilai standar eror sebagai berikut: 


$$
\begin{aligned}
& e i=\sqrt{ }\left(1-\mathrm{Ri}^{2}\right) \ldots \ldots \ldots \ldots \ldots \ldots \ldots \ldots \ldots \\
& \mathrm{Pe}_{1}=\sqrt{ }\left(1-\mathrm{R}_{1}{ }^{2}\right)=\sqrt{ }(1-0,380)=0,787 \\
& \mathrm{Pe}_{2}=\sqrt{ }\left(1-\mathrm{R}_{2}{ }^{2}\right)=\sqrt{ }(1-0,607)=0,626
\end{aligned}
$$

Berdasarkan perhitungan nilai standar eror, didapatkan hasil $\mathrm{Pe}_{1}$ atau standar eror variabel kepuasan pelanggan $\mathrm{e}_{1}$ sebesar 0,787 dan $\mathrm{Pe}_{2}$ atau standar eror loyalitas pelanggan pelanggan e2 sebesar 0,626 . Hasil koefisien determinasi total dihitung sebagai berikut:

$$
\begin{aligned}
\mathrm{R}^{2} \mathrm{~m} & =1-\left(\mathrm{Pe}_{1}\right)^{2}\left(\mathrm{Pe}_{2}\right)^{2} \ldots \ldots \\
& =1-(0,787)^{2}(0,626)^{2} \\
& =0,758
\end{aligned}
$$

Nilai koefisien determinasi total yaitu sebesar 0,758 menginterpretasikan bahwa sebesar 75,8\% variasi loyalitas pelanggan dipengaruhi oleh variasi perceived value dankepuasan pelanggan, lalu sebesar $24,2 \%$ sisanya dijelaskan pada faktor-faktor lain yang tidak termasuk dalam model penelitian.

Sesuai dengan hasil analisis pengaruhperceived valueterhadap kepuasan pelanggan, mendapakan perolehan hasil nilai koefisien beta 0,617 dengan nilai signifikansi sebesar 0,000. Nilai koefisien beta $>0$ dan nilai signifikansi $0,000<$ 0,05 mengindikasikan bahwa perceived value berpengaruh positif dan signifikan terhadap kepuasan pelanggan. Dengan demikian, $\mathrm{H}_{1}$ diterima.

Sesuai dengan hasil analisis pengaruh perceived value terhadap loyalitas pelanggan, mendapatkan perolehan hasil nilai koefisien beta 0,446 dengan nilai signifikansi sebesar 0,000. Nilai koefisien beta > 0 dan nilai signifikansi $0,000<$ 
0,05 mengindikasikan bahwa perceived value berpengaruh positif dan signifikan terhadap loyalitas pelanggan. Dengan demikian, $\mathrm{H}_{2}$ diterima.

Sesuai dengaan hasilanalisis pengaruhkepuasan pelanggan terhadap loyalitaspelanggan, mendapatkan perolehanhasil nilai koefisien beta 0,421 dengannilai signifikansi sebesar 0,000 . Nilai koefisien beta $>0$ dan nilai signifikansi $0,000<0,05$ mengindikasikan bahwa kepuasan pelanggan berpengaruh positif dan signifikan terhadap loyalitas pelanggan. Dengan demikian, $\mathrm{H}_{3}$ diterima.

Tabel 11.

Pengaruh Langsung dan Pengaruh Tidak Langsung serta Pengaruh Total Antar Variabel

\begin{tabular}{cccc}
\hline Pengaruh Variabel & $\begin{array}{c}\text { Pengaruh } \\
\text { Langsung }\end{array}$ & $\begin{array}{c}\text { Pengaruh Tidak Langsung } \\
\text { Melalui Mediasi }\left(\beta_{\mathbf{1}} \mathbf{x} \beta_{\mathbf{3}}\right)\end{array}$ & Pengaruh Total \\
\hline $\mathrm{X} \rightarrow \mathrm{M}$ & 0,617 & - & 0,617 \\
$\mathrm{X} \rightarrow \mathrm{Y}$ & 0,446 & $(0,617 \times 0,421)=0,259$ & 0,705 \\
$\mathrm{M} \rightarrow \mathrm{Y}$ & 0,421 & - & 0,421 \\
\hline
\end{tabular}

Sumber : Data Primer, 2018.

Berdasarkan Tabel 11 dapat dilihat bahwa variabel perceived value memiliki pengaruh langsung terhadap variabel loyalitas pelanggan serta pengaruh tidak langsung melalui variabel kepuasan pelanggan. Jumlah koefisien pengaruh tidak langsung dapat dihitung dengan mengalikan koefisien jalur dari variabel perceived value ke variabel kepuasan pelanggan dengan koefisien jalur variabel kepuasan pelanggan ke variabel loyalitas pelanggan sebesar $(0,617 \times 0,421)=$ 0,259. Hasil koefisien pengaruh tidak langsung lebih kecil dibanding dengan pengaruh langsung, sehingga dapat disimpulkan bahwa variabel kepuasan pelanggan adalah sebagai variabel partial mediation dalam memediasi pengaruh variabel perceived value terhadap variabel loyalitas pelanggan. 
Uji Sobel digunakan untuk menguji signifikansi dari hubungan tidak langsung antara variabel independen dengan variabel dependen yang dimediasi oleh varibel mediator. Setelah itu dilakukan perbandingan antara nilai $\mathrm{Z}$ hitung dengan nilai $\mathrm{Z}$ tabel yaitu sebesar $\geq 1,98$ (dengan taraf kepercayaan sebesar 95 persen). Seumpama nilai $\mathrm{Z}$ hitung lebih besar dibandingkan $\mathrm{Z}$ tabel, maka kesimpulannya terjadi pengaruh mediasi. Berdasarkan perhitungan, didapatkan nilai $\mathrm{Z}$ hitung sebesar 4,5231 yang artinya lebih besar dari $\mathrm{Z}$ tabel yaitu 1,9824 $(4,5231>1,9847)$. Dapat disimpulkan bahwa kepuasan pelanggan mampu memediasi pengaruh perceived value terhadap loyalitas pelanggan.

\section{Tabel 12.}

\section{Hasil Uji Sobel}

\begin{tabular}{ccc}
\hline Sobel & Nilai & Keterangan \\
\hline Z hitung & 4,5231 & Memediasi \\
Sig. & 0,000 & Signifikan \\
\hline
\end{tabular}
Sumber : Data Primer, 2018.

Pada penelitian ini, pengaruh langsung perceived value (variabel independen) terhadap loyalitas pelanggan (variabel dependen) mendapatkan hasil yang signifikan, begitu juga dengan hasil pengaruh tidak langsung melalui variabel mediator yaitu kepuasan pelanggan mendapatkan hasil yang signifikan. Oleh karena baik pengaruh secara langsung dan tidak langsung (melalui mediasi) mendapatkan hasil yang signifikan, maka pada penelitian ini variabel kepuasan pelanggan berperan secara parsial dalam memediasi pengaruh antara variabel perceived value dengan variabel loyalitas pelanggan. 


\section{IMPLIKASI HASIL PENELITIAN}

Implikasi penelitian disini berusaha menekankan pada manfaat nyata dari hasil penelitian untuk mendorong usaha jasa agar tetap mampu memanfaatkan perceived value secara maksimal guna tetap menjaga pelanggan agar tetap puas dengan pelayanan secara keseluruhan sehingga loyalitas para pelanggan mampu dipertahankan. Terdapat beberapa implikasi strategis hasil penelitian ini.

Persepsi nilai atau perceived value merupakan komponen yang mampu meningkatkan kepuasan pelanggan Hotspot Wifi.Id. Penting bagi perusahaan untuk tetap fokus menjaga dan meningkatkan kualitas jaringan agar sesuai dengan harapan pelanggan sehingga dapat meminimalisir keluhan terhadap Hotspot Wifi.Id. Hal ini dapat menjadi strategi perusahaan untuk dapat meningkatkan kepuasan pelanggan dan pada akhirnya akan mendorong timbulnya loyalitas yang positif dari pelanggan Wifi.Id.

Kepuasan pelangganatau customer satisfaction adalah komponen yang memicu timbulnya loyalitas pelanggan. Terjaganya kepuasan pelanggan terhadap layanan yang dberikan Wifi.Id akan mendorong timbulnya loyalitas dari para pelanggan untuk tetap menggunakan Hotspot Wifi.Id. Terpenuhinya harapan pelanggan akan menciptakan persepsi positif membuat konsumen akan melakukan pembelian secara berulang (repurchase), sehingga Hotspot Wifi.Id akan tetap menjadi prioritas utama dibenak para pelanggan.

Loyalitas terbentuk dari penilaian pelanggan terhadap kualitas produk atau jasa yang diterimanya (persepsi) berdasarkan harapan yang telah terkonsep dalam pikirannya. Penilaian konsumen Wifi.Id yang cenderung positif tentunya mengindikasikan bahwa konsumen puas terhadap kualitas layanan Hotspot yang 
diberikan. Situasi lingkungan pemasaran yang bersifat dinamis memungkinkan pelanggan untuk beralih ke produk pesaing, oleh sebab itu perusahaan tidak boleh tinggal diam ketika semata-mata hanya melihat konsumen itu puas terhadap produk Wifi.Id.

Keterkaitan antara perceived value, kepuasan pelanggan dan loyalitas pelanggan dapat dijadikan tolak ukur kepada para pelaku usaha untuk memprediksi bagaimana perilaku konsumen dalam melakukan pemilihan, menyeleksi sampai pada akhirnya menggunakan barang dan jasa. Loyalitas pelanggan bermula dari bagaimana pelanggan menilai kualitas Hotspot Wifi.Id yang diterimanya (persepsi) sesuai denganintensi yang terkonsep dalam pikirannya. Apabila kualitas layanan telah sesuai atau bahkan melebihi harapan (nilai terpersepsi) tentunya akan menimbulkan kepuasan. Konsumen yang merasa puas dengan kualitas Hotspot Wifi.Id yang dia terima tentu akan cenderung menjadikan Hotspot Wifi.Id sebagai prioritas dengan melakukan pembelian ulang (repurchase) bahkan merekomendasikannya kepada pihak lain yang dimana semua itu merupakan indikasi dari pelanggan yang benar-benar loyal.

\section{SIMPULAN DAN SARAN}

Berdasarkan hasil pembahasan, dapat ditarik beberapa simpulan. Pertama, perceived value berpengaruh positif signifikan terhadap kepuasan pelanggan. Hasil penelitian ini menunjukkan bahwa semakin tinggi perceived value pelanggan Wifi.Id, maka semakin tinggi pula kepuasan parapelanggan.Begitupun sebaliknyajika semakinrendah perceivedvalue pelangganWifi.Id, maka semakin rendah pula kepuasan para pelanggan. Kedua,perceived value berpengaruhpositif 
signifikanterhadap loyalitaspelanggan. Hasil penelitian ini menunjukkanbahwa semakintinggi perceived valuepelanggan Wifi.Id, makasemakin tinggipula loyalitaspara pelanggan. Begitupunsebaliknya jikasemakin rendah perceived valuepelanggan Wifi.Id, maka semakin rendah pula loyalitaspara pelanggan. Ketiga, kepuasanpelanggan berpengaruhpositif signifikanterhadap loyalitas pelanggan. Hasil penelitian inimenunjukkan bahwasemakin tinggikepuasan pelanggan Wifi.Id, makasemakin tinggipula loyalitaspara pelanggan. Begitupun sebaliknyajika semakinrendah kepuasanpelanggan Wifi.Id, makasemakin rendahpula loyalitaspara pelanggan.Keempat, kepuasan pelanggan berpengaruh signifikan dalam memediasi pengaruh variabel perceived value terhadap variabel loyalitas pelanggan. Hasil ini menunjukan bahwa perceived value yang dirasakan pelanggan Wifi.Id sesuai dengan kepuasan yang diperoleh pelanggan saat menggunakan layanan Wifi.Id, sehingga timbul loyalitas yang tinggi. Efek mediasi yang terjadi adalah mediasi parsial atau partial mediation karena pada penelitian ini pengaruh perceived value terhadap loyalitas pelanggan secara langsung mendapatkan hasil yang signifikan, begitupun dengan pengaruhnya secara tidak langsung melalui variabel mediasi yaitu kepuasan pelanggan.

Sesuai denganhasil kajiandari simpulan,maka masukanyang dapatdiberikan bagipihak-pihak yangmembutuhkan hasil kajian ini adalah pertama, Wifi.Id diharapan untuk tetap mencermati perceivedbalance antaraharga dari produkdan semuautilitas didalamnya, maka ada baiknya Wifi.Id melakukan penyesuaian sesuai tarif rata-rata yang ada. Kedua, Wifi.Id dituntut untuk mencermati kepuasan pelanggan secara menyeluruh agar pelanggan benar-benar merasa puas. 
Antara lain dengan meningkatkan kualitas jaringan serta menambah fasilitasfasilitas penunjang lainnya sehingga membuat pelanggan tetap nyaman selama berada di Hotspot area. Ketiga, Wifi.Id diharapkan tetap fokus meningkatkan value bagi pelanggan, menarik pelanggan baru serta merespon ancaman pesaing. Keempat, Penelitian berikutnya diharapkan mampu mencari dasar teori serta metodologi yang sesuai agar dapat meningkatkan ketepatan dalam pengumpulan informasi. Kelima, Penelitian berikutnya diharapkan lebih jeli dalam memilih sampel penelitian, sehingga tingkat keakurasian hasil data lebih akurat. Penelitian berikutnya juga diharapkan lebih objektif dalam interpretasi hasil analisis data, sehingga semakin ilmiah investigasi penelitian. Keenam, penelitian berikutnya diharapkan memiliki tujuan yang jelas dalam perumusan masalah, agar peneliti dapat terfokus pada tujuan yang ingin dicapai. Ketujuh, penelitian berikutnya yang akan melakukan penelitian dengan tema sejenis diharapkan melakukan penelitian lebih mendalam dengan memasukan variabel lainnya bahkan menambah jumlah variabel yang diteliti, serta diharapkan mampu mengembangkan model penelitian dandidukung konsep teori maupunisu-isu terbaru. Selain itu,penelitian berikutnya jugadiharapkan mampumengelaborasi ruanglingkup dan lokasipenelitian sehinggadapat digeneralisasi secaraumum.

\section{REFERENSI}


Asosiasi Penyelenggara Jasa Internet Indonesia (APJII). (2017). Infografis Penetrasi dan Perilaku Pengguna Internet di Indonesia (Survey 2017). https://www.google.com/url?hl=id\&q=https://apjii.or.id/survei2017/downl oad/g0WG57ENIHUpBa3vl8d2oVh4j1Z9bT\&source=gmail\&ust=151965 2832502000\&usg=AFQjCNHF6WPT8qd10p4vryvW9WSosmXqzw.

Diunduh tanggal 25, bulan Februari, tahun 2018.

Awwad, M. S. (2012). "An Application of the American Customer Satisfaction Index (ACSI) in the Jordanian Mobile Phone Sector". The TQM Journal. 24(6), pp.529-541.

Barnes, J.G. (2011). Secrets of Customer Relationship Management(Rahasia Manajemen Hubungan Pelanggan). Yogyakarta: Andi Offset.

Bernarto, I., \& Patricia. (2017). Pengaruh Perceived Value, Customer Satisfaction dan Trust terhadap CustomerLoyalty Restoran XYZ di Tangerang.Journal for Business and Entrepreneur. 1(1), h.36-49.

Boonlertvanich, K.. (2011). "Effect Of Customer Perceived Value On Satisfaction And Customer Loyalty In Banking Service: The Moderating Effect Of Main-Bank Status". International Journal Of Business Research. 11(6), pp.40-54.

Briliana, Vita. (2013). Pengaruh Kepuasan, Komitmen, Manfaat Sosial, dan Special Treatment Benefits Terhadap Loyalitas Pelanggan. Jurnal Bisnis dan Akuntansi 1. 15(1), h.57-64.

Candra, L.P. \& Bernarto, I., (2012) ; "Pengaruh Service Quality dan Perceived Value terhadap Satisfaction dan Loyalty", DeReMa Jurnal Manajemen. 7(2), h.19-31.

Castro, C.B., Armario, E.M., \& Ruiz D.M. (2004). Pengaruh Perilaku Kewargaan Organisasional Karyawan pada PT Kesetiaan Pelanggan. Jurnal Internasional Manajemen Industri Jasa. 15(1). h.27-53.

Chen, Ching-Fu \& Tsai, Meng-Huan. (2008). "Perceived Value, Satisfaction and Loyalty of TV Travel Product Shopping: Involvement as a Moderator". Journal Tourism Management. 29, pp.1166-1171.

Chung, F.T., \& Lee, Y.K., (2013), "Online Consumer Loyalty: A Perspective of Electronic Service Quality”, Tajen Journal. 39, pp.65-83.

Dabholkar \& Walls. (1999). Customer Satisfaction And Its Effects On Customer Loyalty. London College of Management Studies. UK. 
El-Adly, M.I. \& Eid, R . (2016). An Empirical Study of The Relationship Between Shoping Environment, Customer Perceived Value, Satisfaction and Loyalty in The UAE Malls context. Journal of Retailing and Customer Service. 31, pp.217-227.

El-Adly, M.I. (2018). Modelling The Relationship Between Hotel Perceived Value, Customer Satisfaction, and Customer Loyalty. Journal of Retailing and Customer Service. 43, pp.1-352

Gultom, W.S.T., Yuliati, S.N., \& Djohar S. (2016). Pengaruh Service Quality, Product Quality dan Perceived Value Terhadap Kepuasan dan Loyalitas Pelanggan Industri Kayu Perhutani. Jurnal Manajemen dan Agribisnis. 13(2), h.109-121.

Hasan, Ali. (2013). Marketing dan Kasus-Kasus Pilihan. Yogyakarta: CAPS (Center For. Academic Publishing Service).

Hasan, H., Kiong, T. P., \& Ainuddin, Raja Azimah. (2014). Effect of Perceived Value and Trust on Customer Loyalty towards Foreign Bank in Sabah, Malaysia. Global Journal of Emerging Trends in e-Business, Marketing and Consumer Psychology, 1 (2), pp: 80-86.

Hellier, K. Phillip, Gus M. Geursen, Rodney A. Carr, John A. (2003). "Customer repurchase intention: A general structural equation model". European Journal of Marketing, 37 (11/12), pp.1762-1800.

Kanagal, N. (2009). "Role of relationship marketing in competitive marketing strategy". Journal of Management and Marketing Research, 2(5), pp.1-17.

Kementerian BUMN. (2017). BUMN hadir di kampus: "Membangun Ekonomi Indonesia Berkeadilan”. Jakarta.

Lee, E.J. \& J.W. Overby. (2004). "Creating value for online shoppers: Implications for satisfaction and loyalty". Journal of Consumer Satisfaction, Dissatisfaction and Complaining Behavior, 17, pp.54-67.

Luarn, P. \& Lin, H. (2003). A Customer Loyalty Model for E-Service Context. Journal of Electronic Commerce Research. 4(4), pp.156-167.

Mardikawati, Woro \& Farida, Naili. (2013). Pengaruh Nilai Pelanggan dan Kualitas Layanan Terhadap Loyalitas Pelanggan, Melali Kepuasan Pelanggan Pada Pelanggan Bus Efisiensi (Studi PO Efisiensi Jurusan Yogyakarta-Cilacap). Jurnal Administrasi Bisnis. 2(1), h.64-75.

Meng, S. M., Liang, G. S., Yang, S. H. (2011). The relationships of cruise image, perceived value, satisfaction, and post-purchase behavioral intention on 
Taiwanese tourists. African Journal of Business Management. 5(1), pp.1929.

Moliner, M.A., Sanchez, J., \& Rodriguez R.M. (2007). Relationship Quality with a Travel Agency: The Influence of the Post-Purchase Perceived Value of a Tourism Package. Tourism and Hospitality Research. 7(3/4), pp.194-211.

Mosavi, Seyed Alireza \& Mahnoosh Ghaedi. (2011). "A survey on the relationships between perceived value and customer advocacy behavior". International Conference on Innovation, Management and Service. IPEDR, 14, pp.249-254.

Orel, Fatma Demirci \& Ali Kara. (2014). "Supermarket self-checkout service quality, customer satisfaction, and loyalty: Empirical evidence from an emerging market". Journal of Retailing and Consumer Service. 21(2), pp.118-129.

Palupi, Nunuk Dwi Garwanti Endang. (2017). Analisis Pengaruh Kepuasan Produk Wisata Terhadap Loyalitas Wisatawan (Studi Kasus Pada Wisatawan DIY). Jurnal Bisnis, Manajemen dan Akuntansi. 4 (2), h.70-77.

Parasuraman, A. \& Dhruv Grewal. (2000). "The Impact of Technology on the Quality- Value-Loyalty Chain: A Research Agenda". Journal of the Academy of Marketing Science, 28 (1), pp.168-174.

Putra, Fabi Yuristra Parama. (2016). Analisis Kepuasan dan Loyalitas Pengguna Indonesia Wifi di PT Telkom Divisi Regional Tiga Jawa Barat. Thesistidak diterbitkan.Jawa Barat: Institut Pertanian Bogor.

Rahab., Handayani S.R., dan Nawarini A.T. (2015). Peran Perceived Value dan Kepuasan Pelanggan Dalam Upaya Membangun Loyalitas Pengguna Kartu Seluler. Media Ekonomi dan Manajemen. 30(1), h.76-84.

Ravald, Annika \& Christian Gronroos. (1996). "The value concept and relationship marketing”. European Journal of Marketing. 30 (2), pp.19-30.

Sawitri, Ni Putu, Yasa, Ni Nyoman Kerti dan Jawas, Abdulah. (2013), Pengaruh Kualitas Pelayanan Terhadap Kepuasan dan Loyalitas Pelanggan Tegal Sari Accommodation di Ubud, Jurnal Manajemen, Strategi Bisnis, dan Kewirausahaan. 7(1), h.40-47.

Setiawan, H., Minarsih M.M., dan Fathoni A. (2016).Pengaruh Kualitas Produk, Kualitas Pelayanan dan Kepercayaan Terhadap Kepuasan Nasabah dan Loyalitas Nasabah Dengan Kepuasan Nasabah Sebagai Variabel Intervening ( Studi Kasus Pada Nasabah Koperasi Rejo Agung Sukses Cabang Ngaliyan ). Journal of Management. 2(2), h.1-17. 
Shoki M., Fen H.S., \& Ismail K. (2012). "Relationship Between Customers' Perceived Values, Satisfaction And Loyalty Of Mobile Phone Users". Review of Integrative Business \& Economic Research. 1(1), pp.126-135.

Sugiati, T., Thoyib, A., Hadiwidjoyo, D., dan Setiawan, M.. (2013). "The Role of Customer Value on Satisfaction and Loyalty (Study on Hypermart's Customers)". International Journal of Business and Management Invention. 2(6), pp.65-70.

Sugiyono. (2016). Metode Penelitian Administratif Dilengkapi Dengan Metode $R \& D$. Bandung: CV. Alfabeta.

Tama, A. W., dan Untoro, W. (2016). Faktor-faktor Pembentuk Loyalitas Merek Pada Pengguna Ponsel Smartfren. Jurnal Economia. 12(2), h.97-112.

Tanujaya, A. (2013). Pengaruh Customer Perceived Value Terhadap Customer Loyalty Melalui Customer Satisfaction Pada 3Second Royal Plaza Surabaya. Jurnal Online, Universitas Katolik Widya Mandala Surabaya, h.1-6.

Tu, Y.T., Li, M.L., \& Chih, H.C. (2013). “An Empirical Study of Corporate Brand Image, Customer Perceived Value and Satisfaction on Loyalty in Shoe Industry“. Journal of Economics and Behavioral Studies. 5(7), pp.469-483.

Wijaya, Andrew. Semuel, Hatane., dan Japarianto, Edwin. (2013). Analisa Pengaruh Perceived Quality terhadap Perceived Value Konsumen Pengguna Internet Mobile XL di Surabaya. Jurnal Manajemen Pemasaran Petra. 1(1), h.1-12.

Wijaya, I Putu Surya Ananta dan Nyoman Nurcaya. (2017). Kepuasan Pelanggan Memediasi Kualitas Produk Dan Kewajaran Harga Terhadap Loyalitas Merek Mcdonalds Di Kota Denpasar. E-Jurnal Manajemen Universitas Udayana. 6(3), h.1534-1563

Woodruff, R.B., \& Gardial S.F. (1996). Know Your Customer: New Approaches To Understanding Customer Value and Satisfaction. Cambridge, MA: Blackwell Publications.

Woodruff, R.B. (1997). "Customer Value: the next sorce for competitive advantages". Journal of the Academy of Marketing Service. 25(2). pp.139153. 
$\mathrm{Wu}$, S.I \& Chen, Y.J. (2014). "The impact of green marketing and perceived innovation on purchase intention for green products", International Journal of Marketing Studies. 6(5), pp.81-100.

Wulandari, Hesti \& Rahyuda, I Ketut. (2016). Peran Kepuasan Pelanggan Memediasi Harga dengan Pelanggan (Studi pada Pelanggan Produk Margarin Merek Blue Band PT. Unilever di Kota Denpasar). E-Jurnal Manajemen Universitas Udayana. 5(5), h.2871-2897.

Yang, Z. \& Peterson, R.T. (2004). “Customer Perceived Value, Satisfaction, and Loyalty: The Role of Switching Costs". Psychology \& Marketing Journal. 21(10), pp.99-822.

Yeung, I.M.H. \& Leung, Stephen.C.H. (2012). "Relationships among Service Quality, Value, Customer Satisfaction and Loyalty in a Hong Kong Harbour Cruise". Journal Department of Management Sciences. 1(1), pp.1-14.

Zeithaml, Valarie A. (1988). "Consumer Perceptions of Price, Quality, and Value: A Means-End Model and Synthesis of Evidence". Journal of Marketing. 52 (7). pp.2-22. 